\title{
Pengaruh Kualitas Pelayanan Bidan Terhadap Kepuasan Pasien KIA di Puskesmas Pangenan Kabupaten Cirebon
}

\author{
${ }^{1}$ Roni Iryadi \\ ${ }^{1}$ Prodi Diploma III Kebidanan Poltekes Bhakti Pertiwi Husada Cirebon \\ Jl. Kampung Melati No.6A Kesambi-Cirebon \\ roniiryadi@gmail.com
}

\begin{abstract}
Abstrak : Tujuan pembangunan kesehatan adalah meningkatkan kesadaran, kemauan dan kemampuan hidup sehat bagi setiap orang agar terwujud derajat kesehatan yang setinggi-tingginya sebagai bagian dari tujuan pembangunan nasional. Penelitian ini bertujuan untuk mengetahui pengaruh kualitas pelayanan bidan terhadap kepuasan pasien KIA di Puskesmas Pangenan Kabupaten Cirebon. Jenis penelitian ini menggunakan desain metode analitik, dengan pendekatan cross sectional dimana variabel independen dan variabel dependen diukur dalam waktu bersamaan. Populasi dalam penelitian ini adalah seluruh ibu hamil pada periode Juli sebanyak 43 Ibu Hamil. Sampel yang digunakan dalam penelitian ini adalah 43 responden. Teknik pengambilan sampel menggunakan total sampling yaitu jumlah populasi yang digunakan juga sebagai sampel, dengan jumlah sampel penelitian yaitu sebanyak 43 responden. Berdasarkan hasil penelitian, dapat diketahui bahwa sebagian besar responden memberikan penilaian baik terhadap kualitas pelayanan bidan yaitu sebanyak 28 responden $(65,1 \%)$. Berdasarkan hasil penelitian dapat diketahui bahwa lebih dari setengah responden memiliki tingkat kepuasan puas yaitu sebanyak 29 responden $(67,4 \%)$. Terdapat pengaruh kualitas pelayanan bidan terhadap kepuasan pasien KIA di Puskesmas Pangenan Kabupaten Cirebon dengan nilai p-value sebesar 0,0001 dimana lebih kecil dari nilai a $(0,05)$.
\end{abstract}

Kata Kunci : : kualitas pelayanan, bidan, kepuasan pasien

Abstract : Health goals are to increase awareness, willingness and ability to lie healthy for everyone to achieve the highest level of health as part of national development goals. This study aims to determine the effect of midwife service quality on the satisfaction of MCH patients at the Cirebon District Health Center. This type of research uses an anilitic method design,with a cross sectional approach where the independent variables and dependent variables are measured at the same time, the population in this study were all KIA patients in July. Sampling technique used an accidental sampling system, with a total sample of 43 respondents. Based on the results of the study, it can be seen that the majority of respondents gave a good aseesment of the quality of the midwife's servants as many as 28 respondents $(65,1 \%)$. Based on the results of the study it can be seen that more than half of the respondents had a level of satisfaction, namely as many as 29 respondents $(67,4 \%)$. There is the influence of the midwife's service quality on the satisfaction of MCH patients at the Pangenan health center in Cirebon district with a p-value of 0,0001 which is smaller than the value of $(0,05)$.

Key Word : service quailty, midwife, patient satisfaction

\section{PENDAHULUAN}

Tujuan pembangunan kesehatan adalah meningkatkan kesadaran, kemauan dan kemampuan hidup sehat bagi setiap orang agar terwujud derajat kesehatan yang setinggi-tingginya sebagai bagian dari tujuan pembangunan nasional. Upaya untuk meningkatkan kualitas pelayanan publik menurut Undang-Undang Republik Indonesia Nomor 25 Tahun 2000 tentang Program Pembangunan Nasional (PROPENAS) adalah melalui penyusunan Indeks Kepuasan Masyarakat (IKM) sebagai tolak ukur untuk mengetahui tingkat kualitas pelayanan publik dengan menilai publik unsur pelayanan sehingga menjadi pendorong bagi setiap unit penyelenggara pelayanan untuk meningkatkan kualitas pelayanannya. Ada 14 unsur pelayanan yang menjadi inti pertanyaan yang harus diukur untuk melihat tingkat kepuasan masyarakat yaitu kesederhanaan proses pelayanan, kesesuaian persyaratan pelayanan, kejelasan dan kepastian petugas yang melayani, kedisiplinan petugas, tanggungjawab petugas, kemampuan petugas, kecepatan pelayanan, keadilan dalam memberikan pelayanan, kesopanan dan keramahan, kewajaran biaya, kesesuaian biaya, ketepatan jadwal, kenyamanan lingkungan dan keamanan lingkungan. 
Salah satu indikator derajat kesehatan masyarakat adalah Angka Kematian Ibu (AKI) karena AKI menggambarkan tingkat kesadaran, perilaku hidup sehari-hari, status gizi dan kesehatan ibu, kondisi lingkungan tingkat pelayanan kesehatan terutama untuk ibu hamil, melahirkan dan nifas. Propinsi Jawa Barat, AKI masih berada pada angka kematian bayi sebanyak 345 per 100.000 kelahiran hidup sedangkan untuk Kota Cirebon tahun 2015 tercatat AKI sebanyak 47 kasus. (Iryadi \& Prihartini, 2019)

Pelayanan kebidanan adalah bagian integral dari sistem pelayanan kesehatan yang diberikan oleh bidan yang telah terdaftar (teregistrasi) yang dapat dilakukan secara mandiri, kolaborasi atau rujukan (Keputusan Menteri Kesehatan Republik Indonesia Nomor 369 / MENKES / SK/ III / 2007).

Berkaitan dengan pelayanan yang bermutu atau berkualitas yang dihubungkan dengan kepuasan, ada lima faktor yang mempengaruhi mutu pelayanan yaitu keandalan (reliability), ketanggapan (responsiveness), jaminan (assurance), empati (empathy) dan keberwujudan (tangibles). Inilah faktor penentu kepuasan pelanggan dimana pelanggan akan membandingkan antara kenyataan (kinerja) dengan harapannya. Pelanggan memang harus dipuaskan, sebab kalau mereka tidak puas mereka akan meninggalkan perusahaan dan menjadi pelanggan pesaing, hal ini akan menurunkan laba dan bahkan menimbulkan kerugian. (Pasaruman, 2001)

Kecenderungan masa kini dan masa depan menunjukkan bahwa masyarakat semakin menyadari perlunya meningkatkan dan mempertahankan kualitas hidup (quality of life). Seiring perkembangan ilmu pengetahuan, sosial dan ekonomi di masyarakat sehingga semakin maju tingkat pendidikan yang kemudian membuat masyarakat dapat memberikan penilaian terhadap apa yang mereka butuhkan. Begitu kompleksnya masalah kehidupan sekarang ini menyebabkan masalah kesehatan benar-benar merupakan kebutuhan penting. Oleh sebab itu, pelayanan kesehatan yang bermutu semakin dicari. Untuk memenangkan persaingan yang semakin ketat tersebut, bidan harus mampu memberikan kepuasan terhadap pelanggan dalam hal ini adalah pasien (Novitasari, 2014).

Bidan ditantang untuk dapat memberikan pelayanan profesinya memenuhi standar Internasional untuk mampu bersaing dengan bidan-bidan negara lain. Bidan ditantang untuk meningkatkan kompetensinya : pengetahuan, sikap profesi dan keterampilannya sesuai dengan perkembangan IPTEK. Bidan dalam pengabdian profesinya di manapun ia berada harus mampu memberikan pelayanan berkualitas dan selalu berusaha meningkatkan performance serta kemampuan berbahasanya

Menurut Butle dalam Setiawan (2007) kepuasan adalah respon berupa perasaan puas yang timbul karena pengalaman menggunakan suatu produk dalam hal ini adalah produk jasa pelayanan asuhan kebidanan berupa pembinaan kesehatan ibu, pelayanan ibu resti yang berupa cakupan pelayanan konseling dan rujukan, persalinan, KB, perawatan ibu nifas, neonatus, bayi dan balita. Jadi kepuasan pasien (ibu hamil, ibu bersalin, ibu nifas dan ibu balita) dalam penelitian ini bisa dikatakan sebagai perasaan puas pasien yang timbul karena pengalaman menggunakan suatu produk layanan kesehatan berupa asuhan kebidanan dari bidan di Puskesmas Pangenan Kabupaten Cirebon.

Dalam pelayanan kesehatan sekarang ini, pasien memiliki hak untuk mendapatkan kepuasan atas pelayanan kesehatan yang diterimanya. Pasien sekarang cenderung kritis dan menuntut pelayanan berkualitas baik. Mengukurkepuasan pasien dapat digunakan untuk evaluasi kualitas atau mutu pelayanan kesehatan. Terlebih saat ini mutu pelayanan kesehatan merupakan suatuhal yang tidak perlu ditawar lagi untuk ditingkatkan.

Pasien dapat merasakan kepuasan apabila pelayanan diperoleh sesuai dengan apa yang diharapkan, dan sebaliknya dapat merasakan kekecewaan jika pelayanan kesehatan yang diperoleh tidak sesuai dengan yang diharapkan. Kondisi tersebut dapat menyebabkan pasien cenderung memilih pelayanan kesehatan yang mengutamakan kepuasan pasien (Pohan, 2015).

Kepuasan pasien merupakan nilai subyektif terhadap kualitas pelayanan yang diberikan. Penilaian kepuasan pasien dilihat dari bagian mutu pelayanan karena upaya mutu pelayanan haruslah dapat memberikan kepuasan, tidak semata mata kesembuhan belaka. Pasien yang puas akan memberi tahu kepada teman, keluarga, tetangga, dan akan datang lagi untuk kontrol atau membutuhkan pelayanan yang lain (Sabarguna, 2015). Dengan mengetahui tingkat kepuasan pasien, manajemen puskesmas dapat melakukan peningkatan mutu pelayanan. Persentase pasien yang menyatakan puas terhadap pelayanan berdasarkan hasil survei dengan instrumen yang baku (Kemenkes, 2015).

Dari studi pendahuluan yang dilakukan peneliti terhadap 10 orang pasien KIA di Puskesmas Pangenan Kabupaten Cirebon didapat data bahwa 6 orang (60\%) ibu mengaku bidan yang pelayanan cukup baik dalam memberikan asuhan kebidanan dan merasa cukup puas sedangkan 4 orang (40\%) menyatakan bahwa pelayanan bidan kurang baik dan mereka merasa kurang puas.

Berdasarkan penelitian yang dilakukan oleh Setyawati D (2017) dalam artikel ilmiahnya yang berjudul Hubungan Pelaksanaan Antenatal Care (ANC) oleh Bidan dengan Kepuasan Pasien BPJS 
pada Ibu Hamil di Poli KIA Puskesmas Limpung Batang dengan hasil ada hubungan pelaksanaan Antenatal Care (ANC) oleh Bidan dengan kepuasan pasien BPJS pada ibu hamil di Poli KIA.

\section{METODOLOGI PENELITIAN}

Desain penelitian yang digunakan dalam penelitian ini adalah deskriptif korelasi dengan pendekatan yang digunakan dalam peneltian ini adalah pendekatan cross sectional (study potong lintang) yaitu suatu pengukuran variabel dependen dan independen dilaksanakan satu kali pada suatu saat (Notoatmodjo, 2014).

Populasi penelitian ini adalah seluruh pasien KIA di Puskesmas Pangenan Kabupaten Cirebon pada periode September 2018 sebanyak 43 orang (Populasi yang diambil oleh peneliti fokus pada ibu hamil).

Analisis bivariat untuk menguji hipotesis penelitian ini adalah analisis UjiChi Kuadrat ( $\chi^{2}$ ) Analisis ini digunakan untuk menguji apakah dua variabel kategorik yang bersifat nominal atau ordinal mempunyai asosiasi atau tidak.

\section{HASIL PENELITIAN DAN PEMBAHASAN}

\section{A. Hasil Penelitian}

Penelitian ini dilakukan di Puskesmas Pangenan Kabupaten Cirebon dengan cara menyebarkan kuesioner kepada 43 responden.

\section{Analisis Univariat}

Analisis univariat dilakukan untuk mengetahui distribusi frekuensi dan presentasi dari variabel yang diamati, yaitu dengan melakukan penghitungan prosentasi untuk mendapatkan gambaran distribusi responden.

a. Kualitas Pelayanan Bidan

Analisis univariat kualitas pelayanan bidan dapat dilihat pada tabel di bawah ini :

Tabel 1: Distribusi Frekuensi Kualitas Pelayanan Bidan Di Puskesmas Pangenan Kabupaten Cirebon

\begin{tabular}{|l|c|c|}
\hline \multicolumn{1}{|c|}{ Kualitas Pelayanan } & Frekuensi & Prosentase \\
\hline Kurang Baik & 3 & $7 \%$ \\
\hline Baik & 12 & $27,9 \%$ \\
\hline Sangat Baik & 28 & $65,1 \%$ \\
\hline Total & $\mathbf{4 3}$ & $\mathbf{1 0 0} \%$ \\
\hline
\end{tabular}

Dari tabel 1 dapat diketahui bahwa kelompok responden terbanyak pada kelompokyang memberikan penilaian sangat baik terhadap kualitas pelayanan bidan yaitu sebanyak 28 responden $(65,1 \%)$.

b. Kepuasan Pasien KIA

Analisis univariat Kepuasan Pasien KIA dapat dilihat pada tabel di bawah ini :

Tabel 2: Distribusi Frekuensi Kepuasan Pasien KIA Di Puskesmas Pangenan Kabupaten Cirebon

\begin{tabular}{|l|c|c|}
\hline \multicolumn{1}{|c|}{ Kepuasan Pasien } & Frekuensi & Presentase \\
\hline Tidak Puas & 1 & 2.3 \\
\hline Cukup & 13 & 30.2 \\
\hline Puas & 29 & 67.4 \\
\hline Total & $\mathbf{4 3}$ & $\mathbf{1 0 0} \%$ \\
\hline
\end{tabular}

Dari tabel 2 dapat diketahui bahwa kelompok responden terbanyak pada kelompok respondendengan kepuasan puas yaitu sebanyak 29 responden $(64,7 \%)$.

2. Analisis Bivariat

Analisa Bivariat dilakukan untuk membuktikan adanya pengaruh kualitas pelayanan bidan terhadap kepuasan pasien KIA di Puskesmas Pangenan Kabupaten Cirebon.

Hasil dari analisis Chi-Square pengaruh kualitas pelayanan bidan terhadap kepuasan pasien KIA di Puskesmas Pangenan Kabupaten Cirebon didapat data output sebagai berikut :

Tabel 3 : Hasil Analisis Chi-Square Pengaruh Kualitas Pelayanan Bidan Terhadap Kepuasan Pasien KIA Di Puskesmas Pangenan Kabupaten Cirebon

\begin{tabular}{|c|c|c|c|c|c|}
\hline $\begin{array}{c}\text { Kualitas } \\
\begin{array}{c}\text { Pelayanan } \\
\text { Bidan }\end{array}\end{array}$ & \multicolumn{3}{|c|}{ Kepuasan Pasien } & Total & $\begin{array}{c}\text { Uji } \\
\text { Statistik }\end{array}$ \\
\hline Kurang Baik & 1 & $\begin{array}{c}\text { Cukup } \\
\text { Puas }\end{array}$ & Puas & & \\
\hline
\end{tabular}




\begin{tabular}{|c|c|c|c|c|c|}
\hline & $33,3 \%$ & $66,7 \%$ & $0 \%$ & $100 \%$ & 0,0001 \\
\hline Baik & 0 & 11 & 1 & 12 & \\
& $0 \%$ & $91,7 \%$ & $8,3 \%$ & $100 \%$ & \\
\cline { 1 - 4 } Sangat Baik & 0 & 0 & 28 & 28 & \\
& $0 \%$ & $0 \%$ & $100 \%$ & $100 \%$ & \\
\hline Total & $\mathbf{1}$ & $\mathbf{1 3}$ & $\mathbf{2 9}$ & $\mathbf{4 3}$ & \\
& $\mathbf{2 , 3} \%$ & $\mathbf{3 0 , 2} \%$ & $\mathbf{6 7 , 5} \%$ & $\mathbf{1 0 0} \%$ & \\
\hline
\end{tabular}

Dari tabel diatas dapat diketahui dari 3 orang responden yang memberikan penilaian kurang baik terhadap kualitas pelayanan bidan, sebanyak 1 orang responden (33,3\%) mempunyai kepuasan yang tidak puas, dan 2 orang responden $(66,7 \%)$ mempunyai kepuasan cukup puas. Dari 12 orang responden yangmemberikan penilaian cukup terhadap kualitas pelayanan bidan, sebanyak 11 orang responden (91,7\%) mempunyai tingkat kepuasan cukup puas dan sisanya sebanyak 1 orang responden (8,3\%) memiliki tingkat kepuasan puas. Dari 28 orang responden yangmemberikan penilaian baik terhadap kualitas pelayanan bidan, seluruhnyamempunyai tingkat kepuasan puas yaitu sebanyak 28 orang (100\%).

Berdasarkan hasil analisis chi square didapatkan nilai p-value (Sig) sebesar 0,0001. Karena nilai dan Sig 0,0001< a 0,05 maka dapat disimpulkan bahwa Ho ditolak sehingga Ha diterima. Artinya hasil penelitian menunjukkan bahwa ada ada pengaruh kualitas pelayanan bidan terhadap kepuasan pasien KIA di Puskesmas Pangenan Kabupaten Cirebon.

\section{B. Pembahasan}

\section{Kualitas Pelayanan Bidan}

Dari tabel 1 dapat diketahui bahwa kelompok responden terbanyak pada kelompok yang yang memberikan penilaian baik terhadap kualitas pelayanan bidan yaitu sebanyak 28 responden $(65,1 \%)$.

Pelayanan kebidanan merupakan seluruh tugas yang menjadi tanggung jawab pratek profesi bidan dalam sistem pelayanan kesehatan yang bertujuan meningkatkan kesehatan ibu dan anak, keluarga berencana dalam rangka mewujudkan kesehatan keluarga dan masyarakat. Pelayanan kebidanan dapat dibedakan menjadi pelayanan kebidanan primer, kolaborasi dan rujukan (Hidayat dan Mufdillah, 2012:14).

Pelayanan kebidanan adalah bagian integral dari sistem pelayanan kesehatan yang diberikan oleh bidan yang telah terdaftar (teregistrasi) yang dapat dilakukan secara mandiri, kolaborasi atau rujukan (Keputusan Menteri Kesehatan Republik Indonesia Nomor 369 / MENKES / SK/ III / 2007).

Berkaitan dengan pelayanan yang bermutu atau berkualitas yang dihubungkan dengan kepuasan, maka menurut Zeithaml dan M.T.Bitner dalam Novitasari (2014), ada lima faktor yang mempengaruhi mutu pelayanan yaitu keandalan (reliability), ketanggapan (responsiveness), jaminan (assurance), empati (empathy) dan keberwujudan (tangibles). Inilah faktor penentu kepuasan pelanggan dimana pelanggan akan membandingkan antara kenyataan (kinerja) dengan harapannya. Pelanggan memang harus dipuaskan, sebab kalau mereka tidak puas mereka akan meninggalkan perusahaan dan menjadi pelanggan pesaing, hal ini akan menurunkan laba dan bahkan menimbulkan kerugian.

Kecenderungan masa kini dan masa depan menunjukkan bahwa masyarakat semakin menyadari perlunya meningkatkan dan mempertahankan kualitas hidup (quality of life). Seiring perkembangan ilmu pengetahuan, sosial dan ekonomi di masyarakat sehingga semakin maju tingkat pendidikan yang kemudian membuat masyarakat dapat memberikan penilaian terhadap apa yang mereka butuhkan. Begitu kompleksnya masalah kehidupan sekarang ini menyebabkan masalah kesehatan benar-benar merupakan kebutuhan penting. Oleh sebab itu, pelayanan kesehatan yang bermutu semakin dicari. Untuk memenangkan persaingan yang semakin ketat tersebut, bidan harus mampu memberikan kepuasan terhadap pelanggan dalam hal ini adalah pasien

Sebagian besar responden memberikan penilaan puas terhadap kualitas pelayanan bidan, salah satunya dapat dipengaruhi oleh tingkat pengetahuan bidan yang ditunjang oleh tingkat pendidikan bidan, dimana tingkat pendidikan bidan berpengaruh terhadap pengetahuan bidan yang membentuk sikap bidan dalam memberikan asuhan kebidanan yang berkualitas.

2. Kepuasan Pasien KIA

Dari tabel 2 dapat diketahui bahwa kelompok responden terbanyak pada kelompok respondendengan kepuasan puas yaitu sebanyak 29 responden $(64,7 \%)$.

Kepuasan pengguna jasa pelayanan kesehatan dipengaruhi oleh beberapa faktor yaitu (a) pemahaman pengguna jasa tentang jenis pelayanan yang akan diterimanya (b) Sikap peduli yang 
ditunjukkan oleh petugas kesehatan (c) Tingginya biaya pelayanan dapat dianggap sebagai sumber masalah bagi pasien dan keluarganya (d) Penampilan fisisk (kerapia) petugas, kondisi kebersihan dan kenyamanan ruangan (e) Jaminan keamanan yang ditunjukkan oleh petugas kesehatan (f) Keandalan dan keterampilan petugas kesehatan dalam memberikan peraawatan (g) Kecepatan petugas dalam memberikan tanggapan terhadap keluhan pasien.

Kepuasan pasien berhubungan dengan mutu pelayanan rumah sakit. Dengan mengetahui tingkat kepuasan pasien, manajemen rumah sakit dapat melakukan peningkatan mutu pelayanan (Depkes RI : 31). Kepuasan pasien dipertimbangkan sebagai salah satu dimensi kualitas yang paling penting dan merupakan kunci sukses dalam organisasi kesehatan seperti puskesmas. Kepuasan pasien dapat diteliti dalam konteks pengalaman keseluruhan pasien terhadap organisasi kesehatan (Alrubaiee dan Alkaa’ida, 2011) dalam Marzaweny, dkk (2012 : 566).

Kepuasan pasien merupakan nilai subyektif terhadap kualitas pelayanan yang diberikan. Penilaian kepuasan pasien dilihat dari bagian mutu pelayanan karena upaya mutu pelayanan haruslah dapat memberikan kepuasan, tidak semata mata kesembuhan belaka. Pasien yang puas akan memberi tahu kepada teman, keluarga, tetangga, dan akan datang lagi untuk kontrol atau membutuhkan pelayanan yang lain.

\section{Pengaruh Kualitas Pelayanan Bidan Terhadap Kepuasan Pasien KIA}

Dari hasil penelitian didapatkan nilai p-value sebesar 0,0001. Karena nilai dan Sig 0,0001< a 0,05 maka dapat disimpulkan bahwa Ho ditolak sehingga Ha diterima. Artinya hasil penelitian menunjukkan bahwa ada ada pengaruh kualitas pelayanan bidan terhadap kepuasan pasien KIA di Puskesmas Pangenan Kabupaten Cirebon.

Kepuasan pasien merupakan nilai subyektif terhadap kualitas pelayanan yang diberikan. Penilaian kepuasan pasien dilihat dari bagian mutu pelayanan karena upaya mutu pelayanan haruslah dapat memberikan kepuasan, tidak semata mata kesembuhan belaka. Pasien yang puas akan memberi tahu kepada teman, keluarga, tetangga, dan akan datang lagi untuk kontrol atau membutuhkan pelayanan yang lain (Sabarguna, 2015).

Dari tabel diatas dapat diketahui dari 3 orang responden yang memberikan penilaian kurang terhadap kualitas pelayanan bidan, sebanyak 1 orang responden (33,3\%) mempunyai kepuasan yang tidak puas, dan 2 orang responden $(66,7 \%)$ mempunyai kepuasan cukup puas. Dari 12 orang responden yang memberikan penilaian cukup terhadap kualitas pelayanan bidan, sebanyak 11 orang responden $(91,7 \%)$ mempunyai tingkat kepuasan cukup puas dan sisanya sebanyak 1 orang responden $(8,3 \%)$ memiliki tingkat kepuasan puas. Dari 28 orang responden yang memberikan penilaian baik terhadap kualitas pelayanan bidan, seluruhnya mempunyai tingkat kepuasan puas yaitu sebanyak 28 orang (100\%).

Pasien dapat merasakan kepuasan apabila pelayanan diperoleh sesuai dengan apa yang diharapkan, dan sebaliknya dapat merasakan kekecewaan jika pelayanan kesehatan yang diperoleh tidak sesuai dengan yang diharapkan. Kondisi tersebut dapat menyebabkan pasien cenderung memilih pelayanan kesehatan yang mengutamakan kepuasan pasien.

Dalam pelayanan kesehatan sekarang ini, pasien memiliki hak untuk mendapatkan kepuasan atas pelayanan kesehatan yang diterimanya. Pasien sekarang cenderung kritis dan menuntut pelayanan berkualitas baik.

Mengukur kepuasan pasien dapat digunakan untuk evaluasi kualitas atau mutu pelayanan kesehatan. Terlebih saat ini mutu pelayanan kesehatan merupakan suatu hal yang tidak perlu drtawar lagi untuk ditingkatkan. Demikian pula menurut BA Molachele (2014) yang mendapatkan adanya hubungan yang berarti antara kepuasan pasien di rawat inap RS Fatmawati dengan pelayanan dokter, pelayanan perawat, fasilitas medis, lingkungan fisik dan makanan yang disediakan.

Sedangkan Supraptono (2014) mendapatkan adanya hubungan yang sangat bermakna antara pelayanan dokter, perawat dan pelayanan administrasi terhadap kepuasan pasien. Dari data di atas tingkat kepuasan banyak dikaji pada untuk pelayanan kesehatan rumah sakit dan belum dieksplisitkan rawat jalan atau rawat inap sehingga sampai sejauh ini masih minim informasi tentang kepuasan pasien baik rawat jalan maupun rawat inap yang dikaitkan dengan faktor eksternal dan internal pasien.

Kepuasan merupakan perasaan seseorang yang senang atau kecewa yang dihasilkan dari membandingkan suatu kinerja yang dirasakan sesuai dengan harapannya. Kualitas pelayanan bidan dapat mempengaruhi persepsi pasien tentang pelayanan puskesmas yang merupakan faktor penting penentu kepuasan pasien. Pasien dapat merasakan kepuasan apabila pelayanan diperoleh sesuai dengan apa yang diharapkan, dan sebaliknya dapat merasakan kekecewaan jika pelayanan kesehatan yang diperoleh tidak sesuai dengan yang diharapkan. Kondisi tersebut 
dapat menyebabkan pasien cenderung memilih pelayanan kesehatan yang mengutamankan kepuasan pasien.

Variabel Kepuasan hidup dibentuk berdasarkan empat indikator, yaitu goals/tujuan-tujuan, mood/optimisme, health/kesehatan diri, finances/ jaminan finansial. Sementara variabel kepuasan pasien dibentuk berdasarkan lima indikator, yaitu : hubungan dokter-pasien/dokter patient relationship, kenyamanan pelayanan/amenities, kebebasan memilih/ choice, pengetahuan dan kompetensi teknis/scientific knowledge and technical skill, efektifitas pelayanan/effectiveness dan dimensi keamanan tindakan/safety.

Pasien beranggapan bahwa dengan pelayanan yang baik dan jasa yang berkualitas sehingga mereka merasakan kepuasan yang sesuai dengan harapan yang mereka persepsikan, maka apapun keadaan pasien tidak lagi menjadi masalah yang penting cepat sembuh dari penyakitnya.

Tingkat kepuasan dipengaruhi oleh beberapa faktor diantaranya adalah pemberi jasa (provider) dan pelanggan atau konsumen. Faktor pemberi jasa (provider) ini terdiri dari aspek medis dan aspek non medis. Faktor pelanggan atau konsumen (customer) dipengaruhi oleh umur, jenis kelamin, pendidikan dan lain-lain. Derajat kepuasan pelanggan dipengaruhi oleh latar belakang pelanggan, kedudukan sosial, tingkat ekonomi, budaya, pendidikan, umur dan jenis kelamin.

Penelitian ini sesuai dengan hasil penelitian dari Dewi Meilana tentang Pengaruh Kualitas Pelayanan pada Kepuasan Pasien di Puskesmas Tanjung Mas Makmur Lampung Tahun 2017.

\section{KESIMPULAN DAN SARAN}

Berdasarkan hasil penelitian terdapat beberapa hal yang dapat disimpulkan yaitu :

1. Lebih dari setengah responden memberikan penilaian baik terhadap kualitas pelayanan bidan yaitu sebanyak 28 responden $(65,1 \%)$.

2. Berdasarkan hasil penelitian dapat diketahui bahwa lebih dari setengah responden memiliki tingkat kepuasan puas yaitu sebanyak 29 responden $(64,7 \%)$..

3. Terdapat pengaruh kualitas pelayanan bidan terhadap kepuasan pasien KIA di Puskesmas Pangenan Kabupaten Cirebon dengan nilai p-value sebesar 0,0001.

\section{SARAN}

1. Bagi Puskesmas

Penelitian ini dapat memberikan referensi bagi puskesmas sebagai bahan evaluasi mengenai kepuasan pasien.

2. Bagi Pasien KIA

Diharapkan hasil penelitian ini memberikan pengetahuan bagi ibu untuk memanfaatkan pelayanan kesehatan yang terdapat di puskesmas semaksimal mungkin sehingga dapat meningkatkan derajat kesehatan ibu dan anak.

3. Bagi Tenaga Kesehatan / Bidan

Diharapkan hasil penelitian ini bermanfaat untuk tenaga kesehatan dan agar dapat meningkatkan asuhan pelayanan kebidanannya dengan baik.

\section{DAFTAR PUSTAKA}

Alrubaiee, L., \& Alkaa'ida, F. 2011. The mediating effect of patient satisfaction in the patients' perceptions of health care quality - patient trust relationship.International Journal of Marketing Studies, pp. 103-127.

Boy S, Sabarguna. 2015. Quality Assurance Pelayanan Rumah Sakit. Jakarta: Sagung Seto.

Iryadi, R., Prihartini, A. R., \& Irmawati, S. (2019). Hubungan Mutu Pelayanan Kebidanan dengan Kepuasan Pasien di Ruang Rawat Inap Kebidanan. Jurnal Kesehatan Pertiwi, 1(2), 48-52.

Keputusan Menteri Kesehatan Republik Indonesia Nomor 369 / MENKES / SK/ III / 2007

Marzaweny, D. 2012. Analisis Kepuasan Pasien Sebagai Mediasi Pengaruh Kualitas Pelayanan Kesehatan Terhadap Citra Rumah Sakit Umum Daerah Arifin Achmad Pekan Baru. Jurnal Aplikasi Manajemen. Vol. 10. No. 3, Hal. 564.

Mufdlilah., Hidayat. A., Kharimaturrahmah, I. 2012. Konsep Kebidanan. Yogyakarta: Nuha Medika

Parasuraman, A. Valerie, (2001). (Diterjemahkan oleh Sutanto) Delivering Quality Service. The Free Press, New York.

Setiawan, M.B., dan Ukudi., 2007, Pengaruh Kualitas Layanan, Kepercayaan dan Komitmen terhadap Loyalitas Nasabah, Jurnal Bisnis dan Ekonomi (JBE), Vol. 14, No.2, September 2007. 